\title{
Article \\ Competitive Real-Time Near Infrared (NIR) Vein Finder Imaging Device to Improve Peripheral Subcutaneous Vein Selection in Venipuncture for Clinical Laboratory Testing
}

\author{
Mark D. Francisco ${ }^{1,2,3,+}$, Wen-Fan Chen ${ }^{4,+}$, Cheng-Tang Pan ${ }^{2,5,+}$, Ming-Cheng Lin ${ }^{2,6}$, Zhi-Hong Wen ${ }^{7}$, \\ Chien-Feng Liao ${ }^{8, *}$ and Yow-Ling Shiue ${ }^{1,5, *(\mathbb{D})}$ \\ 1 Institute of Biomedical Sciences, National Sun Yat-sen University (NSYSU), Kaohsiung 80424, Taiwan; \\ markfrancisco_trinity@mem.nsysu.edu.tw \\ 2 Department of Mechanical and Electro-Mechanical Engineering, NSYSU, Kaohsiung 80424, Taiwan; \\ pan@mem.nsysu.edu.tw (C.-T.P.); leo1127@mem.nsysu.edu.tw (M.-C.L.) \\ 3 College of Medical Technology, Trinity University of Asia (TUA), Quezon City 1102, Philippines \\ 4 Institute of Medical Science and Technology, NSYSU, Kaohsiung 80424, Taiwan; sallychen@imst.nsysu.edu.tw \\ 5 Institute of Precision Medicine, NSYSU, Kaohsiung 80424, Taiwan \\ 6 Department of Mechanical Engineering, R.O.C. Military Academy, Kaohsiung 83059, Taiwan \\ 7 Department of Marine Biotechnology and Resources, NSYSU, Kaohsiung 80424, Taiwan; \\ wzh@mail.nsysu.edu.tw \\ 8 Department of Emergency Medicine, Kaohsiung Armed Forces General Hospital, \\ Kaohsiung City 80284, Taiwan \\ check for \\ updates \\ * Correspondence: enqvist122929@gmail.com (C.-F.L.); shirley@imst.nsysu.edu.tw (Y.-L.S.) \\ + Co-first Authors.
}

Citation: Francisco, M.D.; Chen, W.-F.; Pan, C.-T.; Lin, M.-C.; Wen, Z.-H.; Liao, C.-F.; Shiue, Y.-L. Competitive Real-Time Near Infrared (NIR) Vein Finder Imaging Device to Improve Peripheral Subcutaneous Vein Selection in Venipuncture for Clinical Laboratory Testing. Micromachines 2021, 12, 373. https:// doi.org/10.3390/mi12040373

Academic Editor: Niall Tait

Received: 19 February 2021

Accepted: 22 March 2021

Published: 30 March 2021

Publisher's Note: MDPI stays neutral with regard to jurisdictional claims in published maps and institutional affiliations.

Copyright: (c) 2021 by the authors. Licensee MDPI, Basel, Switzerland. This article is an open access article distributed under the terms and conditions of the Creative Commons Attribution (CC BY) license (https:// creativecommons.org/licenses/by/ $4.0 /)$.

\begin{abstract}
In this study, near-infrared (NIR) technology was utilized to develop a low-cost real-time near infrared (NIR) guiding device for cannulation. A portable device that can be used by medical practitioners and also by students for their skills development training in performing cannulation. Methods. First, is the development of a reflectance type optical vein finder using three (3) light emitting diode (LED) lights with $960 \mathrm{~nm}$ wavelength, complementary metal-oxide-semiconductorinfrared (CMOS-IR) sensor camera with $1920 \times 1080$ UXGA (1080P), IR filter set for the given wavelength, and an open-source image processing software. Second, is the actual in-vitro human testing in two sites: the arm and dorsal hand of 242 subjects. The following parameters were included, such as gender, age, mass index (BMI), and skin tone. In order to maximize the assessment process towards the device, the researchers included the arm circumference. This augmented subcutaneous vein imaging study using the develop vein finder device compared the difference in the captured vein images through visual and digital imaging approaches. The human testing was performed in accordance with the ethical standards of the Trinity University of Asia-Institutional Ethics Review Committee (TUA-IERC). Results. The NIR imaging system of the developed vein finder in this study showed its capability as an efficient guiding device through real-time vein pattern recognition, for both sites. Improved captured vein images were observed, having $100 \%$ visibility of vein patterns on the dorsal hand site. Fourteen (5.79\%) out of 242 subjects reported non-visible peripheral subcutaneous veins in the arm sites. Conclusions. The developed vein finder device with the NIR technology and reflected light principle with low-energy consumption was efficient for real-time peripheral subcutaneous vein imaging without the application of a tourniquet. This might be utilized as a guiding device in locating the vein for the purpose of cannulation, at a very low cost as compared to the commercially available vein finders. Moreover, it may be used as an instructional device for student training in performing cannulation.
\end{abstract}

Keywords: (NIR) near-infrared; (LED) light emitting diode; vein finder; deoxyhemoglobin; cannulation; venipuncture; image processing 


\section{Introduction}

Through the years, the application of light emitting diode (LED) in the field of medical healthcare is highly utilized, primarily due to its efficiency. Vein finders were developed as guiding device in locating the vein for cannulation. In general, approximately $90-95 \%$ of hospital patients receive their treatment through intravenous route (IV) of administration [1]. Moreover, more than one billion venipunctures are being performed annually for medical laboratory testing [2]. The said procedures were performed through cannulation. It is a technique in which a cannula is placed inside a vein to provide venous access for blood sampling, drug, fluids, and nutrition administration [3]. In order to perform this procedure, the first step is to make the target vein visible, usually by using a tourniquet or by slightly tapping the site [4]. However, not all of the veins are visible, because they lack the distinguishing color or venous distention of the skin surface, even after the application of a tourniquet [5].

There are three veins that can be seen in the antecubital fossa. Among the three veins at the center of the arm is the median cubital, which should be the first choice, followed by the veins in the lateral aspect (outer thumb side), which is the cephalic vein, and the last are the veins in the medial aspect (inner little finger side), the basilic vein [6]. The median cubital vein is considered as the best site for venipuncture. It serves as a branching between the two other veins [7], described to be well anchored, and usually large and prominent [8]. These were the veins that were observed during the prototype testing with emphasis on the median cubital vein [9]. Figure 1 shows the antecubital fossa with the veins for venipuncture.

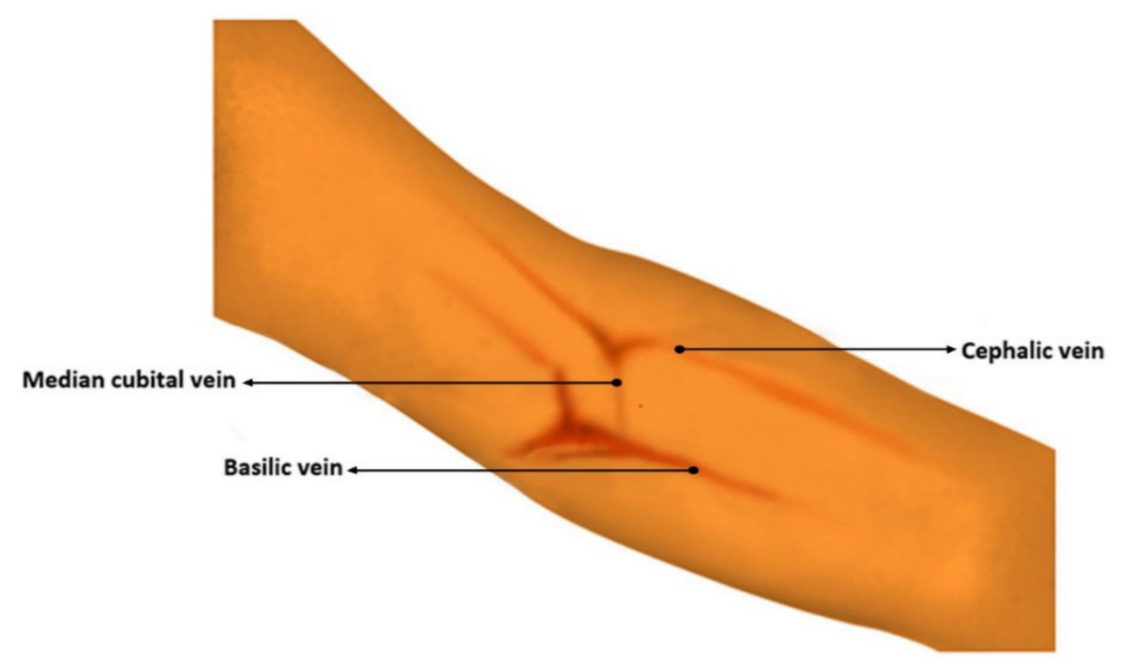

Figure 1. Main veins of the antecubital fossa.

Cannulation is considered to be challenging for many clinicians and other medical practitioners to successfully complete it on the first attempt [10], due to the following factors, which causes difficulty during the performance; such are dehydration, dark skin pigmentation, obesity, poor vein quality, aging, and young age, including the low skill of the personnel performing the procedure [11]. This Peripheral Difficult Venous Access (PDVA) is common, and it occurs frequently in clinical settings due to poorly visualized subcutaneous veins [12] causing unsuccessful and prolonged procedure that can lead to patient's distress, trauma, subcutaneous hemorrhage from frequent attempts, pain, and even unavoidable extreme reactions from children, adults, or patients with mental illness $[4,13]$. Moreover, failures in this procedure are considered to be the possible sources of variability in the medical laboratory test results. They are parts of the pre-analytical phase errors with the highest percentage of $46.00 \%$ up to $77.10 \%$, when compared to the analytical and post-analytical phases [14-20]. 
A vein finder device is primarily composed of a high power NIR-LED, which is the light source, an infrared-sensitive camera, a sensor to capture and format the acquired image real time [21], and a filter for purification by blocking unwanted wavelengths [22-27]. To mention, in previous studies, a low-cost LED as light source with complementary metaloxide-semiconductor (CMOS) imaging sensors was utilized for spectrally encoded confocal microscopy (SECM) as an example of Reflectance confocal microscopy (RCM), a technology for acquiring confocal images [28]. This technology was primarily developed to provide a clearer visible image of the superficial veins. There are two basic principles for vein finders: the reflected light and transillumination. The reflected light type is commonly applied to hand-vein scanners and other commercial devices. The light from the source is reflected in the focused site, and the image is captured by a light sensitive camera at a given wavelength. For transillumination, the light is allowed to penetrate the skin and tissue of the site, and it is then followed by image captured by a camera [27]. The light source can be considered to be the main component of the device. With the electromagnetic spectrum's range of $740 \mathrm{~nm}$ to $940 \mathrm{~nm}$, the light can penetrate to about $5 \mathrm{~mm}$ deep of the skin tissue reaching the subcutaneous vein [29] together with the fat cells, arteries, and nerves [30]. Skin penetration of light is with various wavelengths (Figure 2). The lower wavelength of 200-400 nm can only reach the epidermis skin layer, while 400-600 nm up to the dermis skin layer, and 600-700 $\mathrm{nm}$ can reach the skin subcutaneous tissue [31,32]. Moreover, a variety of lasers and light sources other than the pulsed dye laser (PDL) are useful in the treatment of vascular lesions: continuous and millisecond pulsed lasers with wavelengths between green and yellow $532 \mathrm{~nm}$ and 585-600 nm, near infrared lasers 755-nm, 800-810-nm diode, 1064-nm [33].

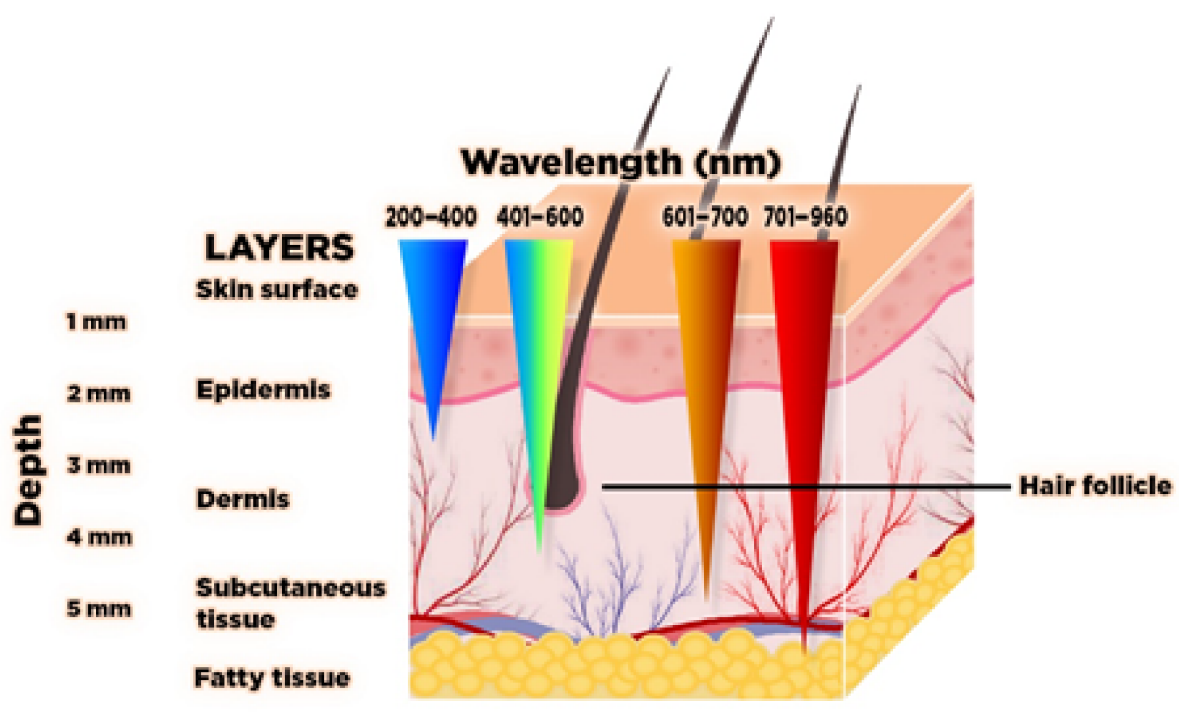

Figure 2. Light skin penetration with different wavelengths (nm).

Veins are blood vessels that function to transport deoxygenated blood back to the heart [26]. This deoxygenated blood with hemoglobin forms a dark contrast to the skin tissue, because of the absorption of the NIR light making veins more visible [29]. NIR is considered to be a low energy, less reactive wavelength of light widely used for safe clinical use [34].

The development of a low-cost vein finder utilizing the near infrared region (NIR) of the electromagnetic spectrum has become popular. It is to primarily address the concern with the cost of a commercial vein finder with an estimated value of about 4500 USD for portable type to $\sim 27,000$ USD for non-portable [35]. Currently, a more convenient model for daily use with optional stand to free the hands of the person performing the cannulation procedure is available at a price range of 4000 USD to 7000 USD per unit [36]. To mention some of the commercialized vein finders are the AccuVein AV300 (AccuVein 
LLC, Cold Spring Harbor, NY, USA), Vein Viewer (Luminetx, Memphis, TN, USA), [22], VascuLuminator, and the [12]. Previous studies show the capability of vein finders to gain more accurate vein course visualization. Unfortunately, it is not widely utilized, due to the cost of commercially available devices [37].

More so, the objective of the study is to develop an efficient low-cost portable device that can be primarily used as an instructional tool in training students performing cannulation.

It is a non-skin contact vein finder prototype that establishes real-time clear venous images, especially with individuals having non-palpable or visible peripheral subcutaneous vein for fast venous access and success in the first attempt in cannulation. Additionally, to aid in eliminating pre-analytical phase errors in the medical laboratory associated with venipuncture that affects the integrity of laboratory test results.

\section{Materials and Methods}

This section describes the method used in the study. It is composed of two phases: first is the development of a low-cost effective vein finder prototype, and, second, is the actual in-vitro human testing with the device in two different sites, the arm and dorsal hand of 242 volunteers to maximize the assessment process. A tourniquet was not used during the experiment, in order to maintain the non-skin contact technique. The captured images from the device with the Vds Vein display system 4.0 software were used for vein mapping and analysis. The human testing was performed in accordance with the ethical standards of the Trinity University of Asia-Institutional Ethics Review Committee (TUA-IERC), with regard to personal data protection and a subject's confidentiality.

\subsection{Device Design with Its Components}

The performed experiment for wavelength selection showed that near infrared light rays of $960 \mathrm{~nm}$ exhibit high absorption with deoxyhemoglobin and deep penetration, achieving the aimed subcutaneous vein visibility. A $1.5 \mathrm{~V}$ DC battery powered the three (3) pieces of LED light source. The arrangement of the 3 NIR LEDs is set at a distance of $2.0 \mathrm{~cm}$. It is attached to the camera with $3.5 \mathrm{~cm}$ distance from the center, giving the overall diffusion and even radiance. A $\frac{1}{2} \cdot 7^{\prime \prime}$ CMOS based sensor camera with $1920 \times 1080$ UXGA (1080P) was used. CMOS as IR detector is characterized by high uniformity, low noise, low power consumption, low cost, and high-speed performance/faster readout [38]. The IR filter was set to essentially block other wavelengths outside the NIR range while allowing light with $960 \mathrm{~nm}$ to pass through. The reflected light imaging principle was applied, which makes the device more compact with the light source attached to the camera. A laptop computer was utilized as the image processing unit (IPU) with Vds Vein display system 4.0 (open-source software) for processing the captured vein image. In image edge detection, this software allows for accurately capturing image in the pixel and checking color change degree of each pixel to distinguish the boundary. Based on the differences of each pixel grayscale, various objects within the image can have obvious edge distinguishing features in their boundaries. Additionally, a simple convolutional filter was used to detect the horizontal and vertical luminosity changes on the image, and the value of each point was calculated by the weighted average to determine the edge. Moreover, window technology in the medical image field, including window width and window center, were used to select the range of image values of interest, it is because various arm surface structures have different image values. When a certain surface structure was displayed, the window width and window position suitable for observing the target site can be chosen to obtain the best display. In the device operation, the vein images were clearly captured with an optimal working distance of $15-20 \mathrm{~cm}$ preventing direct skin contact and giving adequate space for the phlebotomist in performing venipuncture. The model device was attached to a transportable stand to free both hands of the user to perform cannulation. Figure 3 shows the details of the device design. As compared to $10 \mathrm{~cm}$ working distance, uneven power distribution was seen with "green color" on the left and "blue color" on the right 
areas, while, in $25 \mathrm{~cm}$, working distance negative spots for power distribution with "white color" was noted, see Figure 4. The relationship between the working distance and power distribution was analyzed at $1.5 \mathrm{~cm}, 3.5 \mathrm{~cm}$, and $5.5 \mathrm{~cm}$ CMOS Lens-LED configurations. The result showed an inversely proportional relationship, as the distance increases, the power decreases. Moreover, it was observed that, at $15 \mathrm{~cm}$ working distance with 10 $14 \mathrm{~mW}$, the power distribution using three LEDs was comparable to five LEDs and seven LEDs at $20 \mathrm{~cm}$ and $25 \mathrm{~cm}$, respectively. On this regard, it is signified that three LEDs are sufficient to supply the required 10-14 $\mathrm{mW}$ power for vein imaging, see Figure 5. As to the required power strength of 10-14 $\mathrm{mW}$, it was reached and showed equal distribution in different CMOS Lens-LED distances $1.5 \mathrm{~cm}, 3.5 \mathrm{~cm}$, and $5.5 \mathrm{~cm}$ using three LEDs, contrary to five LEDs and seven LEDs that have higher power strength in $3.5 \mathrm{~cm}$ CMOS Lens-LED distance as compared to $1.5 \mathrm{~cm}$ and $5.5 \mathrm{~cm}$, with results shown in Figure 6a-c. Moreover, the variations in power distribution values with different LED-LED distances, such as $1 \mathrm{~cm}$, $2 \mathrm{~cm}, 3 \mathrm{~cm}$, and $4 \mathrm{~cm}$, were analyzed and revealed less than $1 \%$ standard distribution (SD) values. The $10 \mathrm{~cm}$ working distance has the lowest SD value, but the power is $24 \mathrm{~mW}$, which is far higher than 10-14 mW power required for the device. With this, the $15 \mathrm{~cm}$ working distance having $13.124 \mathrm{~mW}$ in $2 \mathrm{~cm}$ LED-LED distance was noted to be sufficient in consideration of the power strength that is shown in Figure 7.

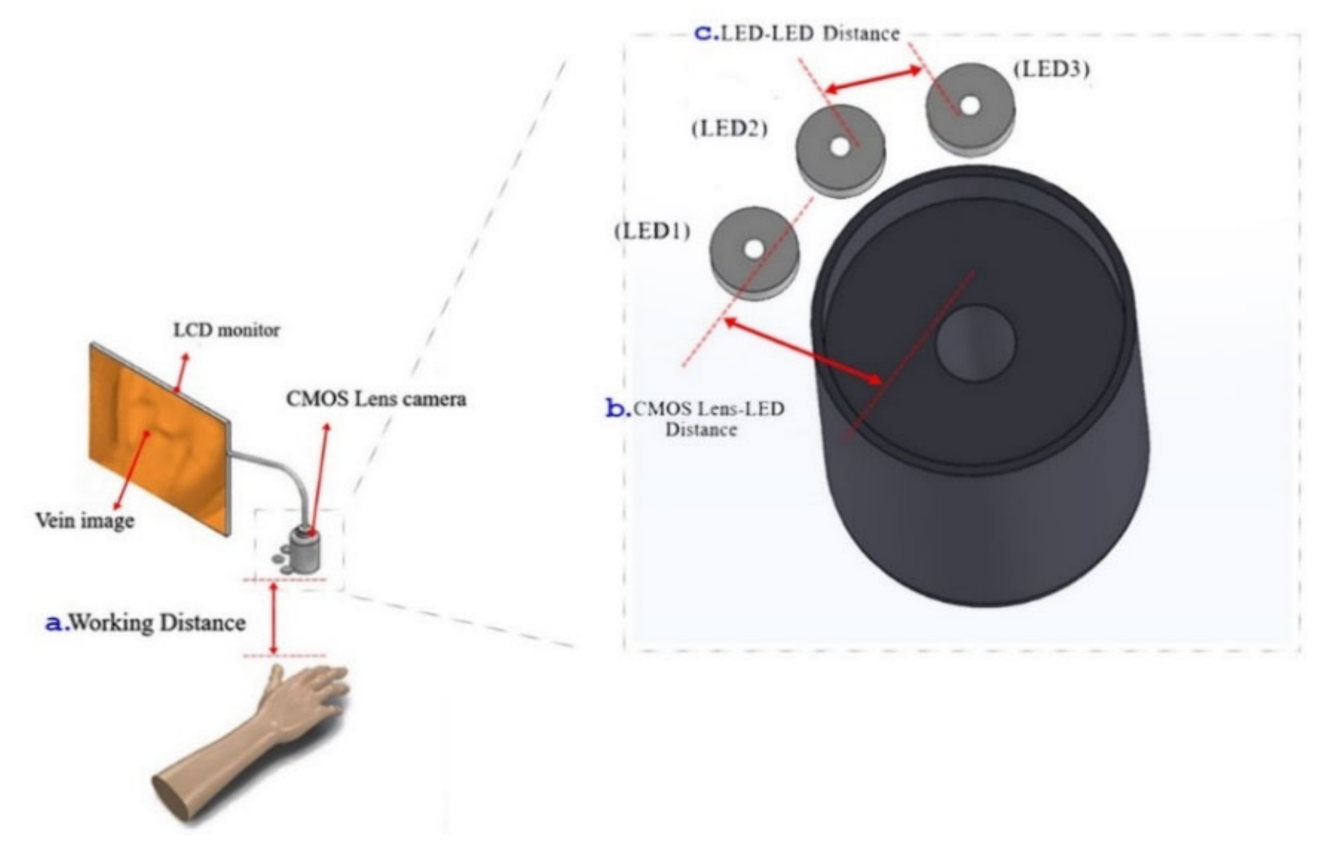

Figure 3. Schematic diagram of the vein finder device design. 


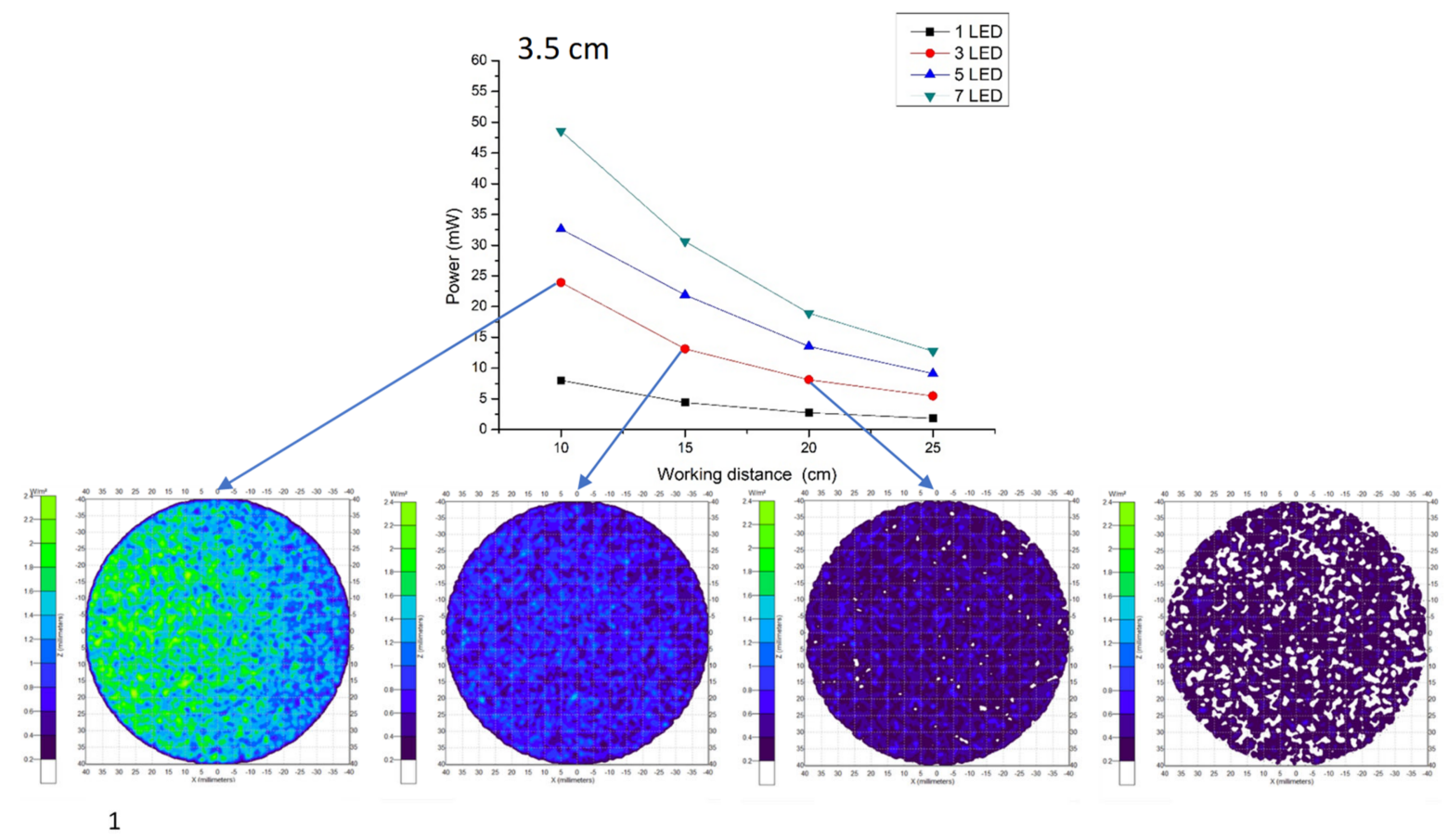

Figure 4. Light emitting diode (LED) power distribution at $3.5 \mathrm{~cm}$ CMOS Lens-LED configuration in different working distances.
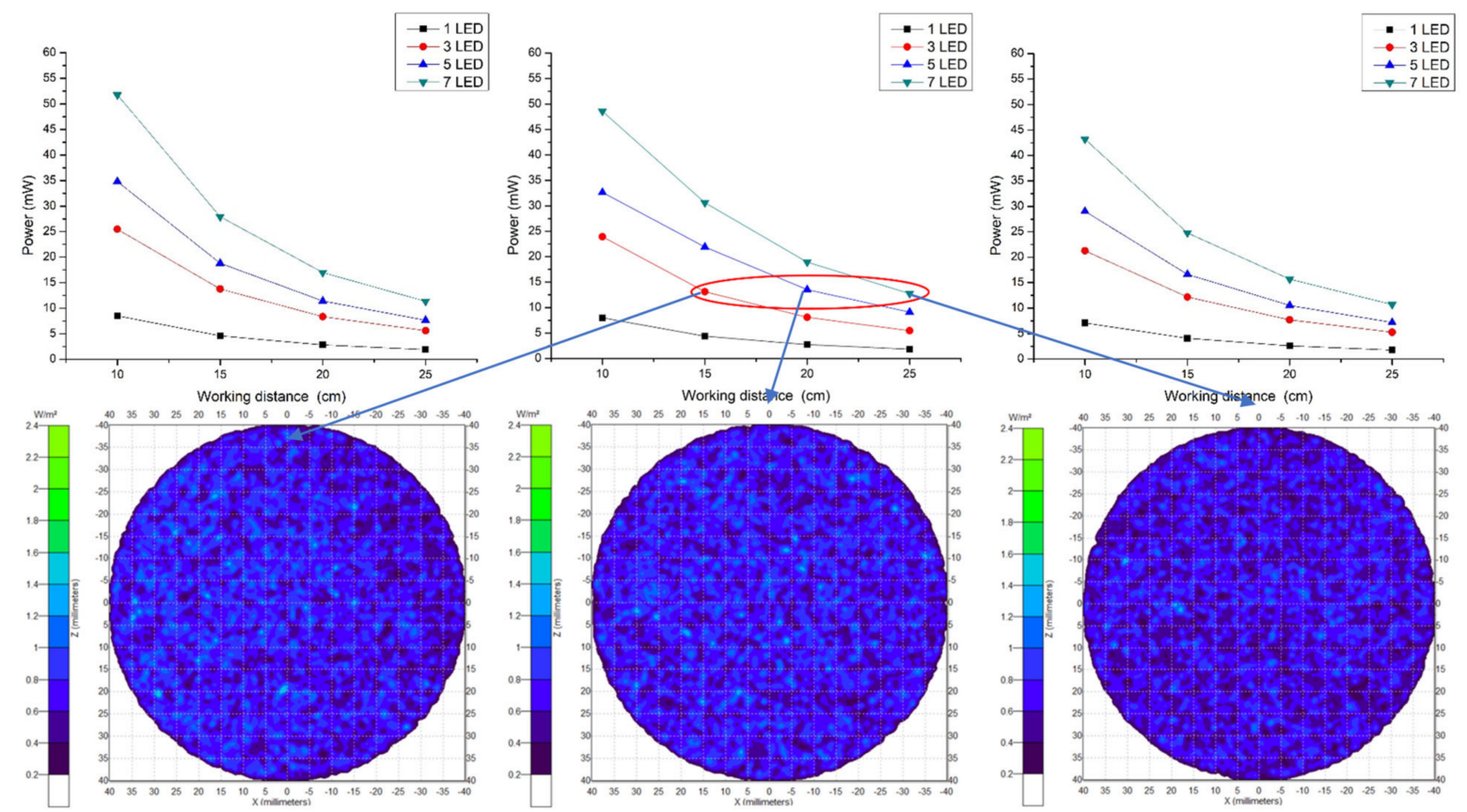

1

Figure 5. Relationship between working distance and the number of LEDs used. 


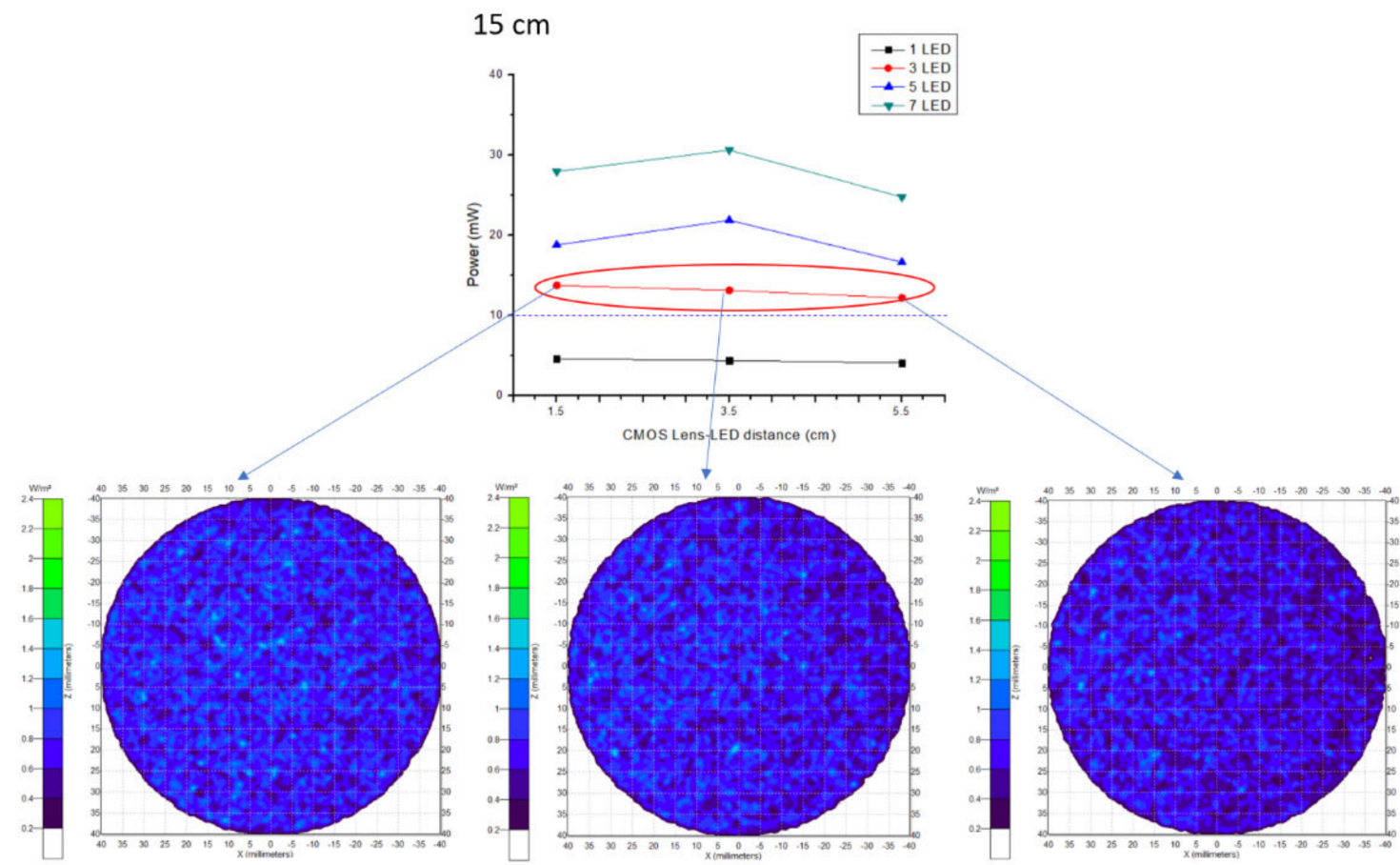

(a)

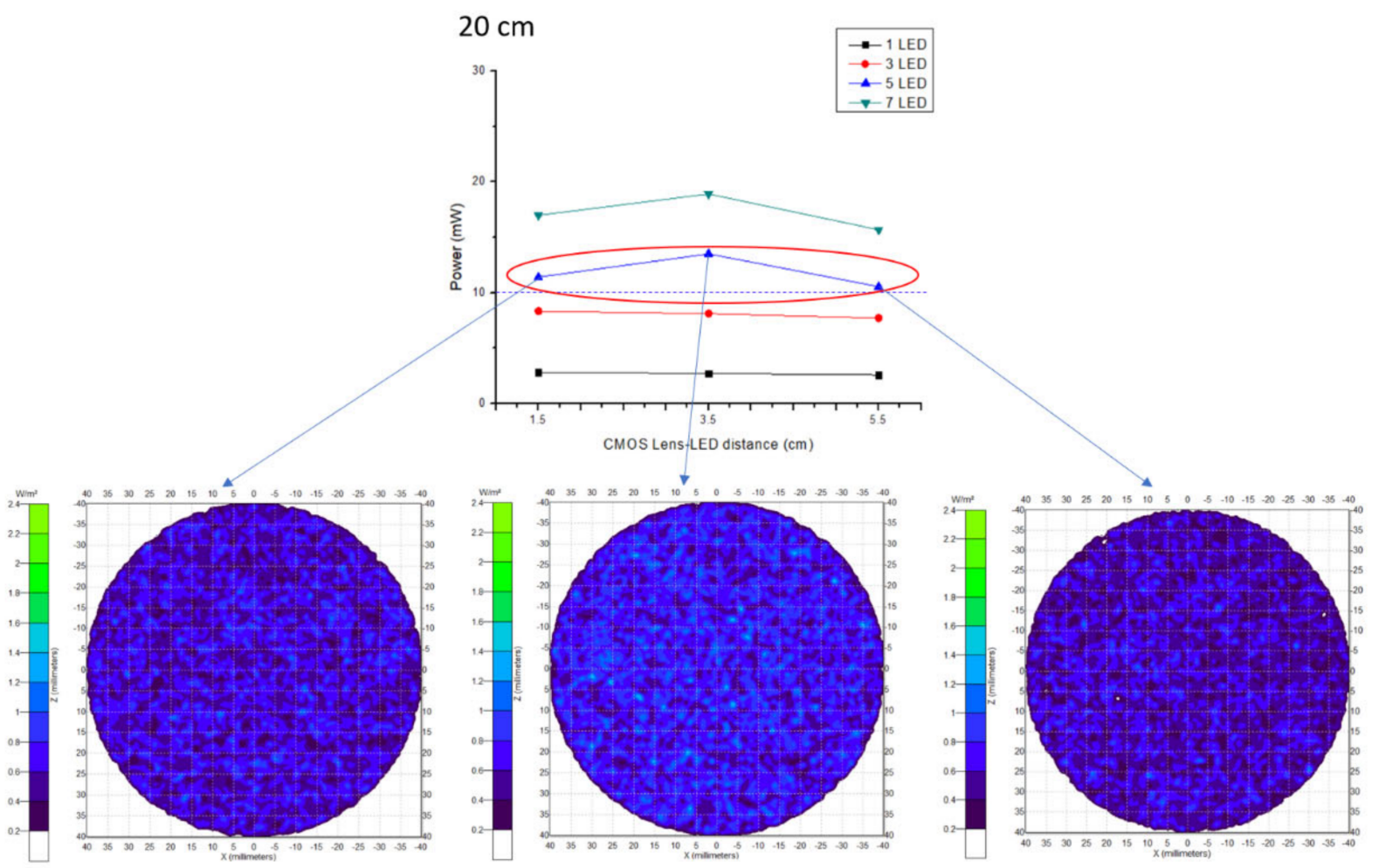

(b)

Figure 6. Cont. 


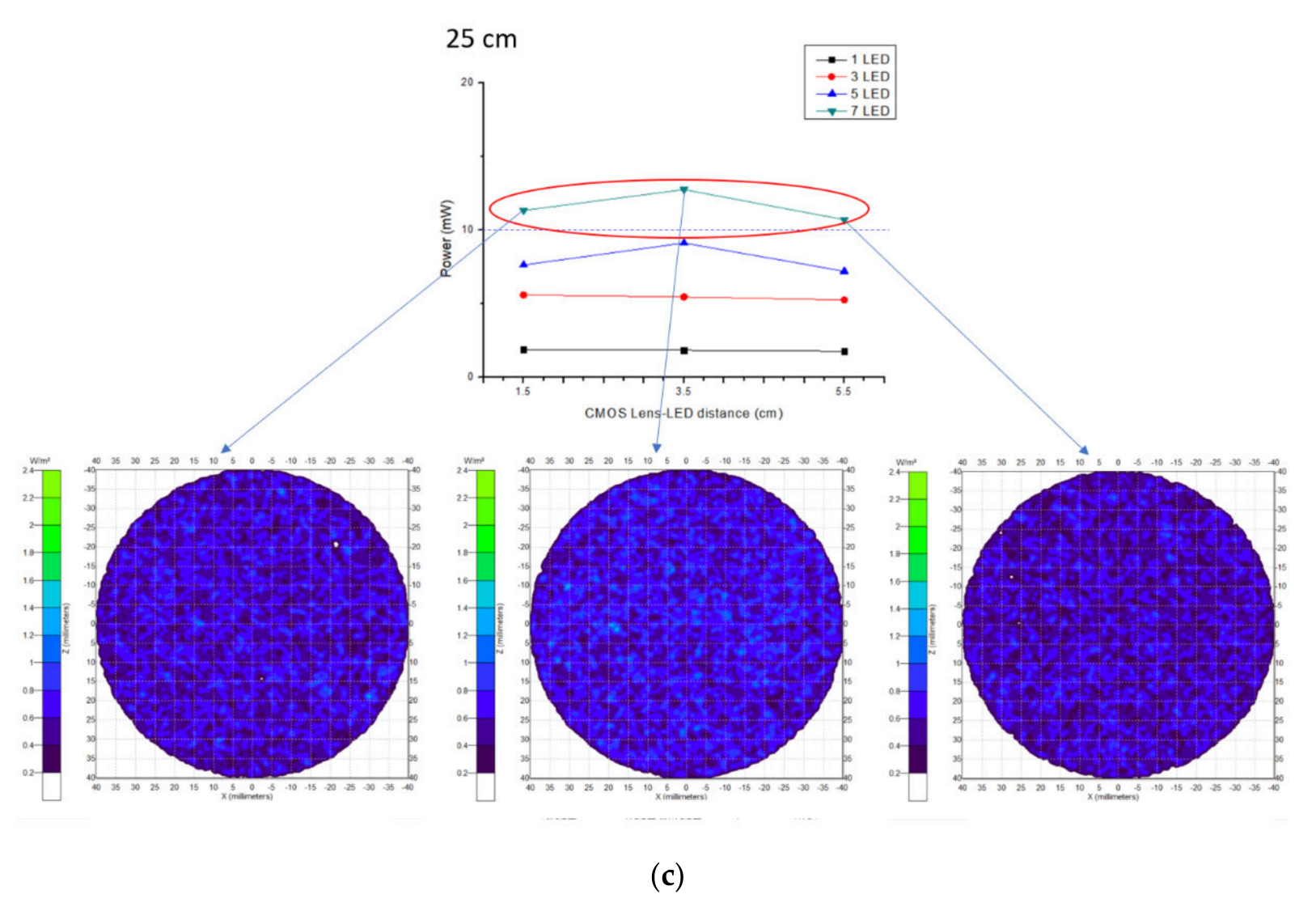

Figure 6. Power strength with different CMOS Lens-LED distances (a-c).

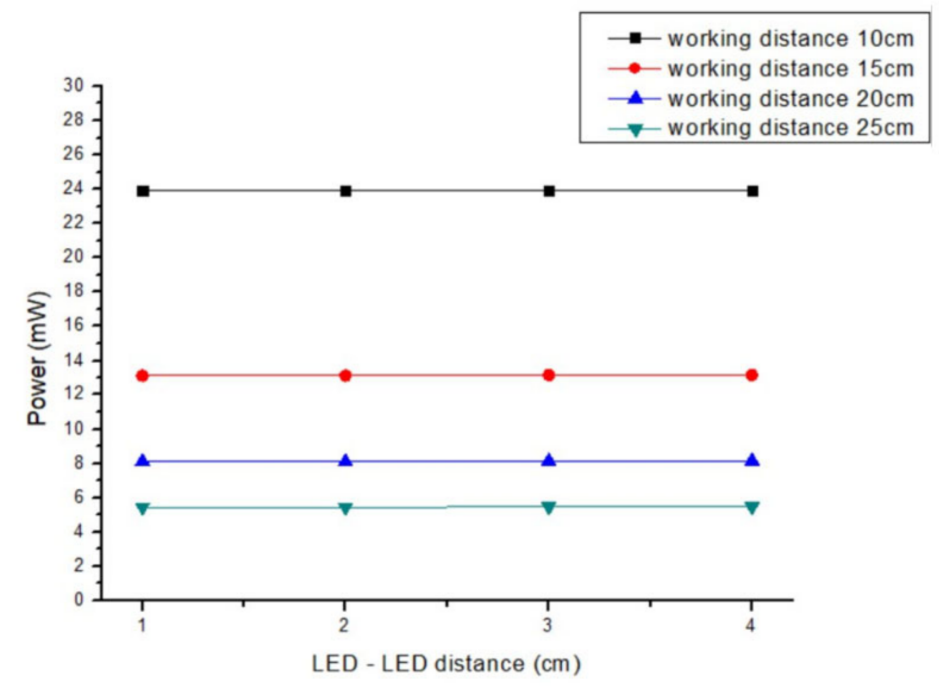

\begin{tabular}{|c|c|c|c|c|c|c|}
\hline \multirow{4}{*}{\begin{tabular}{c} 
cm P(mW) \\
\multirow{3}{*}{3 LED }
\end{tabular}} & LED distance $1 \mathrm{~cm}$ & LED distance $2 \mathrm{~cm}$ & LED distance 3 cm & LED distance 4 cm & Standard deviation \\
\cline { 2 - 7 } & 10 & 23.84 & 23.841 & 23.836 & 23.834 & $0.029 \%$ \\
\cline { 2 - 7 } & 15 & 13.08 & 13.124 & 13.113 & 13.107 & $0.130 \%$ \\
\cline { 2 - 7 } & 20 & 8.0948 & 8.1382 & 8.111 & 8.0883 & $0.617 \%$ \\
\hline
\end{tabular}

Figure 7. Power distribution in different LED-LED distances.

\subsection{Assessment of the NIR Vein Finder Prototype (Image Analysis)}

A total of 242 subjects / participants were enrolled in the study in the actual in-vitro testing of the developed vein finder device. The subjects' demographics, such as gender, 
age, height, and weight for the body mass index (BMI), including the skin tone, were considered as parameters, the same with the previous studies $[5,11,13,22,31,38-41]$, and with the inclusion of arm circumference measurement by the researchers in this study to maximize the assessment process. Specifically, two sites were selected; the arm and dorsal hand for testing, because the subcutaneous veins in the said areas are commonly used for venous blood specimen collection for laboratory testing and intravenous (IV) route for therapy, respectively.

The gathered images were evaluated by direct visual analysis performed by a practicing medical technologist and instructor of phlebotomy course in order to validate the capability of the developed vein finder. It was completed based on the criteria set by the researchers, as described in Figures 8 and 9, and subjects' age, body mass index (BMI), and skin tone/color.

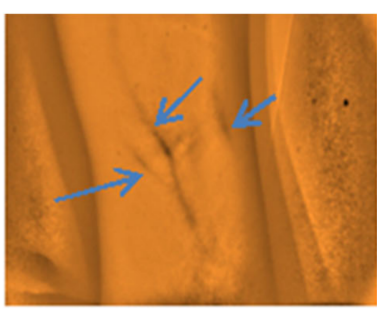

(a)

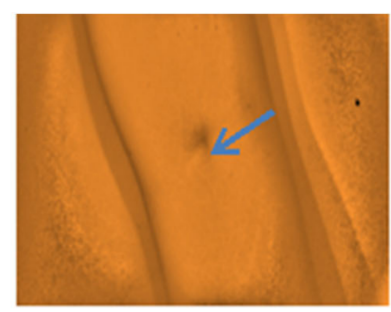

(b)

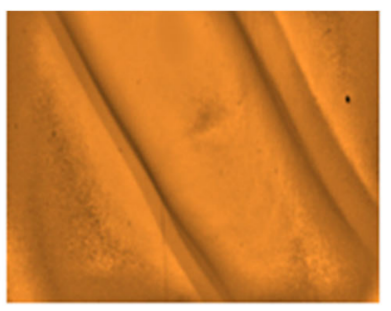

(c)

Figure 8. The types of captured images as results from the arm site. (a) Highly visible, (b) Visible, and (c) Non-visible using the developed vein finder.

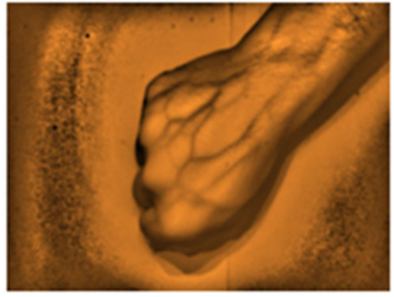

(a)

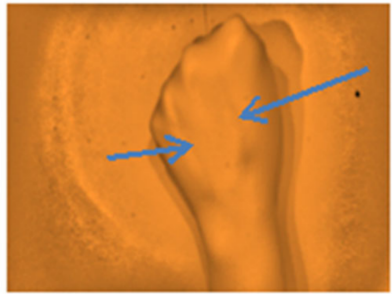

(b)

Figure 9. The types of captured images as results from the dorsal hand site. (a) Highly visible and (b) Visible using the developed vein finder.

The captured subcutaneous vein images were classified based on the working definitions used in the study, (a) highly visible-the vein structure, as seen vividly in the arms of the subject and are enhanced using the vein finder, (b) visible-the veins' image as seen after using the vein finder, and (c) non-visible-the veins' image is not seen, even with the use of the device. In Figure 10, the difference between the captured vein images in the arm and dorsal hand sites using the two (2) approaches, visual and digital imaging approach, were quantitively compared while applying the ImageJ software, and the results showed a remarkable difference of area: $<1$ in both sites (visual approach), while a result of area: 12,865 and area: 5112 (digital imaging approach) in arm and dorsal hand sites, respectively. It indicates the improvement with regard to peripheral subcutaneous vein visibility using the developed vein finder. 


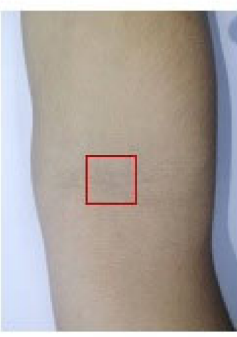

(a)

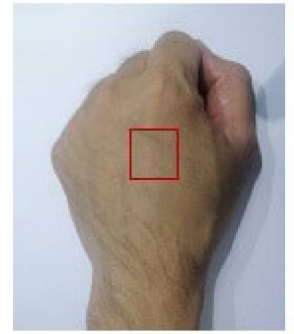

(b)

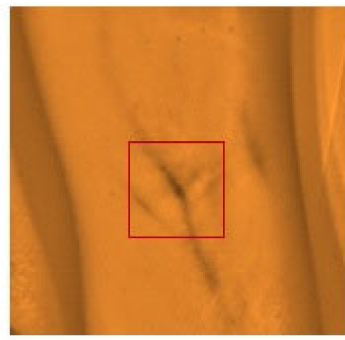

(c)

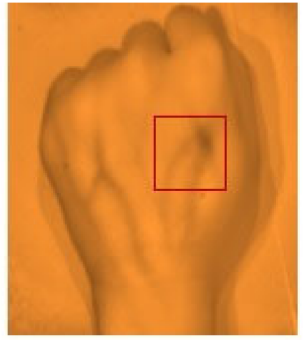

(d)

Figure 10. Peripheral subcutaneous vein imaging through visual approach (without the NIR veinfinder) (a) arm site (area: $<1$ ) and (b) dorsal hand site (area: $<1)$ compared to the digital imaging approach (with the NIR vein finder) (c) arm site (area: 12865) and (d) dorsal hand site (area: 5112). The ImageJ software (National Institutes of Health, Bethesda, MD, USA) was used to quantify vein visibilities.

The sample population were grouped according to age, as follows: Child 0-15, Young adult 16-30, Middle-aged adult 31-50, and Senior adult $>50$ [42], as to BMI which is defined as an estimate of the body fat content based on two factors, the height, and weight for calculation for both male and female were group into: Underweight $<18.5$, Normal 18.5-22.9, Overweight 23.0-24.9, and Obese $\geq 25.0$ [43]. It is useful for this study to indicate the characteristic of being overweight and obesity. While for the skin color/tone classification: Very light complexion I, Light complexion II, Medium complexion III, Darker complexion IV, Dark complexion V, and Black complexion VI was used. This is based on the skin color/tone meter proposed by Thomas B. Fitzpatrick in 1975. It is compared on a person's skin color and was used as a standard by healthcare professionals and aesthetic practitioners in the assessment of their patients [44].

\subsection{Statistical Analysis}

A study with a total of 242 human subjects was performed to evaluate the capability of the developed vein finder device, specifically for vein imaging and mapping in the arm and dorsal hand sites with consideration of gender, age, height, and weight for the body mass index (BMI), skin tone, and the arm circumference measurement as variables. All of the given variables were presented as frequency counts and in percentages that were utilized for the results analysis.

\section{Results}

3.1. Vein Visualization Rate with the Developed Vein Finder in the Arm and Dorsal Hand Sites

In the arm site, 110 (45.45\%) are highly visible, 118 (48.76\%) are visible, and 14 (5.79\%) are non-visible, while, in the dorsal hand site, a result of 121 (50.00\%) is equal for both highly visible and visible, while $0(0.00 \%)$ for non-visible, as shown in Figure 11.

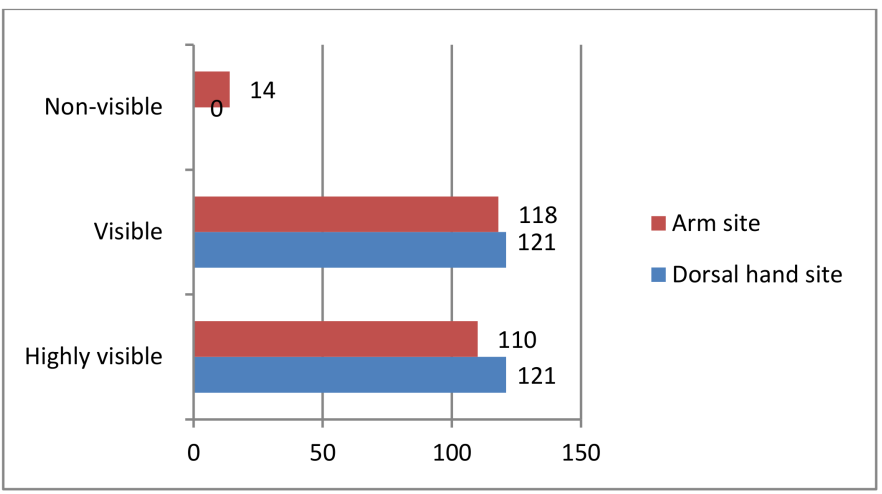

Figure 11. Vein visualization rate with the developed vein finder: $242(100 \%)$ human subjects. 
3.2. Assessment of the Vein Finder with the Different Parameters such as: Gender, Age, Body Mass Index (BMI), Skin Color/Tone, and Arm Circumference

These are the parameters that can be considered to be variables that may affect the capability of the vein finder to locate the subcutaneous veins in the site for cannulation.

3.2.1. Arm Site: Results for Highly Visible and Visible Were Presented Based on the Given Parameters

There were $56(63.64 \%)$ males out of 88 subjects and $54(38.57 \%)$ out of 140 females which yielded highly visible results, while $32(36.36 \%)$ males and $86(61.43 \%)$ females yielded a visible classification presented in Table 1 . This shows that, according to gender, males have vividly visible vein structures as compared to females. Moreover, the markedly increased visible result in female subjects suggests that the vein finder has the capability to make their subcutaneous arm veins visible.

Table 1. Highly visible and visible according to gender.

\begin{tabular}{cccc}
\hline & No. of Subjects & Highly Visible & Visible \\
\hline Male & 88 & 56 & 32 \\
Female & 140 & 54 & 86 \\
TOTAL & 228 & 110 & 118 \\
\hline
\end{tabular}

Table 2 presents significantly increased number of visible results of six $(60.00 \%)$ out of 10 subjects and $22(61.00 \%)$ out of 36 subjects, in the child and middle-aged adult group, respectively. This shows that, according to age, the vein finder was able to improve visibility of veins in the arm site in child and middle-aged adult group while, higher results for highly visible were seen in young adult with 87 (50.28\%) out of 173 and senior adult classification with 5 (55.55\%) out of nine.

Table 2. Highly visible and visible according to age.

\begin{tabular}{ccccc}
\hline & & No. of Subjects & Highly Visible & Visible \\
\hline Child & $0-15$ & 10 & 4 & 6 \\
Young adult & $16-30$ & 173 & 87 & 86 \\
Middle-aged adult & $31-50$ & 36 & 14 & 22 \\
Senior adult & $>50$ & 9 & 5 & 4 \\
TOTAL & & 228 & 110 & 118 \\
\hline
\end{tabular}

Table 3 presents a significantly increased number of visible results of $55(67.07 \%)$ out of 82 subjects in obese classification. This indicates that according to BMI the device was able to improve subcutaneous vein visibility in the arm site even in human subjects with increased BMI scores. While, as expected, a highly visible vein result of 47 (63.51\%) out of 74 was seen on subjects with normal BMI score.

Table 3. Highly visible and visible according to BMI.

\begin{tabular}{ccccc}
\hline & & No. of Subjects & Highly Visible & Visible \\
\hline Underweight & $<18.5$ & 23 & 12 & 11 \\
Normal & $18.5-22.9$ & 74 & 47 & 27 \\
Overweight & $23.0-24.9$ & 39 & 20 & 19 \\
Obese & $\geq 25.0$ & 82 & 27 & 55 \\
& & 218 & 106 & 112 \\
\hline
\end{tabular}

Table 4 presents a significantly increased number of visible results of $68(51.13 \%)$ out of 133 and five $(100.00 \%)$ out of five in darker and dark complexion, respectively. This shows that according to skin color/tone classification, the vein finder was able to improve 
subcutaneous vein visibility even in human subjects with increased skin pigmentation. Additionally, it was noted that the device was able to improve visibility even in human subjects with light complexion, showing a result of four $(66.67 \%)$ visible out of six.

Table 4. Highly visible and visible according to skin color/tone.

\begin{tabular}{ccccc}
\hline & & No. of Subjects & Highly Visible & Visible \\
\hline Light complexion & II & 6 & 2 & 4 \\
Medium complexion & III & 84 & 43 & 41 \\
Darker complexion & IV & 133 & 65 & 68 \\
Dark complexion & V & 5 & 0 & 5 \\
TOTAL & & 228 & 110 & 118 \\
\hline
\end{tabular}

Table 5 presents significantly increased number of visible results of $8(80.00 \%)$ out of 10 and $46(51.69 \%)$ out of 89 in human subjects with $34-30 \mathrm{~cm}$ and $29-25 \mathrm{~cm}$ arm circumference, respectively. This specifies that, according to the given classification, the device was able to improve subcutaneous vein visibility in human subjects, even with larger arm circumference size.

Table 5. Highly visible and visible according to arm circumference.

\begin{tabular}{cccc}
\hline In Centimeter $(\mathbf{c m})$ & No. of Subjects & Highly Visible & Visible \\
\hline $30-34$ & 10 & 2 & 8 \\
$25-29$ & 89 & 43 & 46 \\
$20-24$ & 123 & 62 & 61 \\
$15-19$ & 6 & 3 & 3 \\
TOTAL & 228 & 110 & 118 \\
\hline
\end{tabular}

\subsubsection{Arm Site: Results for Non-Visible Were Presented Based on the Given Parameters}

There was a total of 14 (5.79\%) out of 242 subjects observed with non-visible peripheral subcutaneous veins. Table 6 shows the 14 subjects with their results based on the parameters (gender, age, BMI, skin tone, and arm circumference), which are considered to be potential confounders for the non-visibility of their veins in the arm site. With the 14 subjects, as to gender, the majority are female, eight $(57.14 \%)$, as to age, many are in the young adult group, eight $(57.14 \%)$, under obese classification, there are eight $(57.14 \%)$, with darker complexion seven $(50.00 \%)$, while seven $(50.00 \%)$ are within the $25-29 \mathrm{~cm}$ range group for arm circumference, and some arms of the subjects were observed with stretch marks, three $(21.43 \%)$, and skin marks, two $(14.29 \%)$.

Table 6. Human subjects 14 (5.79\%) with Non-visible subcutaneous veins.

\begin{tabular}{|c|c|c|c|c|c|c|}
\hline Ref No. & Gender & Age & BMI & Skin Tone & $\begin{array}{c}\text { Arm } \\
\text { Circumference }\end{array}$ & Remarks \\
\hline 011 & $\mathrm{~F}$ & 20 & $\mathrm{O}$ & III & 29 & Stretch marks \\
\hline 046 & M & 21 & $\mathrm{O}$ & IV & 26 & Obese, Darker complexion \\
\hline 058 & $\mathrm{M}$ & 19 & $\mathrm{O}$ & IV & 29 & Skin marks \\
\hline 060 & $\mathrm{~F}$ & 19 & $\mathrm{O}$ & IV & 27 & Skin marks \\
\hline 069 & $\mathrm{M}$ & 19 & $\mathrm{O}$ & IV & 31 & Obese, Darker complexion \\
\hline 095 & M & 50 & $\mathrm{O}$ & IV & 33 & Obese, Medium complexion \\
\hline 112 & $\mathrm{~F}$ & 18 & $\mathrm{~N}$ & III & 24 & Tiny/deep vein * \\
\hline 125 & $\mathrm{~F}$ & 34 & $\mathrm{O}$ & IV & 26 & Obese, Darker complexion \\
\hline 131 & $\mathrm{~F}$ & 21 & UW & III & 21 & Tiny/deep vein * \\
\hline 228 & $\mathrm{~F}$ & 20 & $\mathrm{~N}$ & III & 21 & Tiny/deep vein * \\
\hline 232 & M & 39 & $\mathrm{O}$ & IV & 29 & Stretch marks \\
\hline 233 & M & 67 & OW & $\mathrm{V}$ & 26 & Stretch marks \\
\hline 241 & $\mathrm{~F}$ & 13 & NA & III & 23 & Child, Tiny/deep vein * \\
\hline 245 & $\mathrm{~F}$ & 2 & NA & III & 15 & Child, Tiny/deep vein * \\
\hline
\end{tabular}


Furthermore, the researchers would like to report other observations that were noted from the analysis of the captured images with the non-visible results. The arms with the presence of stretch marks, highly pigmented spot with epidermal melanin [5], and from obese (BMI) subjects with darker complexion (Type IV) skin tone affects the visibility of the peripheral veins on the site, as presented in Figures 12-14, respectively. Additionally, a non-visibility from subjects with normal BMI can be attributed to the depth of the vein that is more than $5 \mathrm{~mm}$ [29], and in child age group, due to the tiny vein structure with the presence of thicker subcutaneous tissues [22]. Figures 15 and 16 present the said findings. In contrary, in Figure 17 as observed by the researchers, it is worth to mention that, even in the presence of hair structures in the dorsal hands of the three subjects, the imaging device was still capable of clearly mapping the veins, it is able to prevent the formation of a reflectance glare that can severely impair the vein contrast [41].

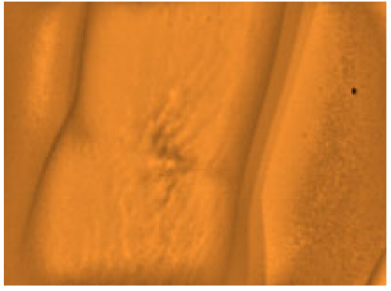

(a)

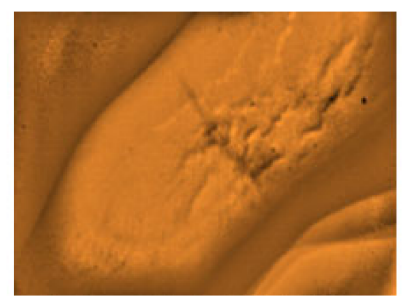

(b)

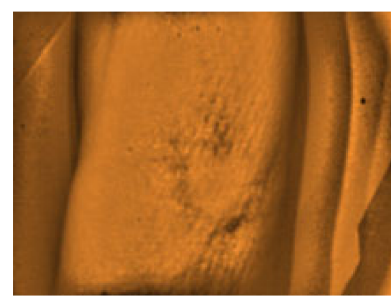

(c)

Figure 12. Arm images from three different subjects with stretch marks with non-visible vein $(\mathbf{a}-\mathbf{c})$.

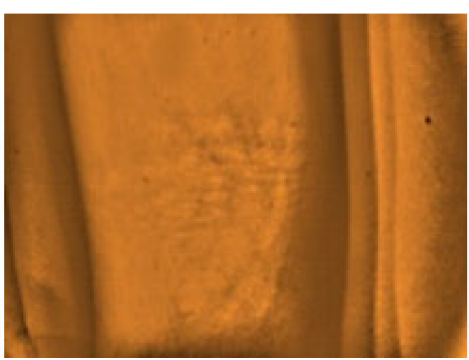

(a)

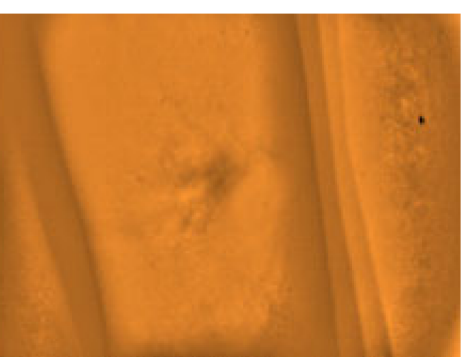

(b)

Figure 13. Arm images of two different subjects with skin marks due to a highly pigmented spotepidermal melanin with non-visible vein $(\mathbf{a}, \mathbf{b})$.

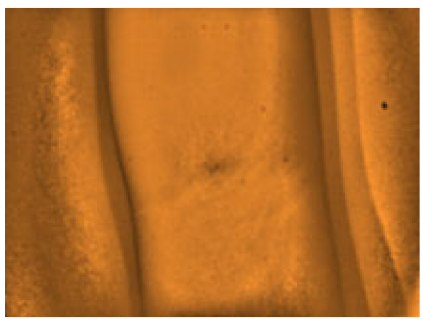

(a)

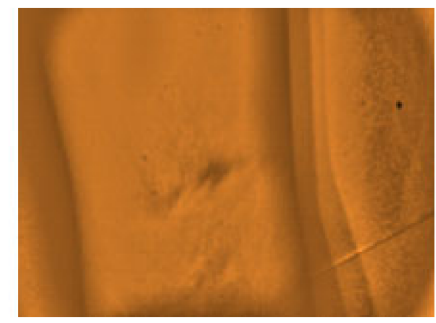

(b)

Figure 14. Arm images of two different subjects $\mathrm{BMI}=\mathrm{O}$, darker complexion (IV) skin tone with non-visible vein $(\mathbf{a}, \mathbf{b})$. 


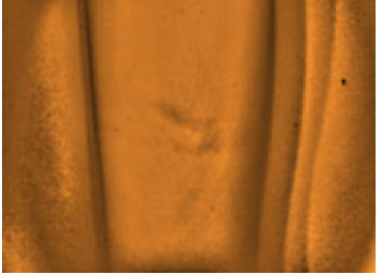

(a)

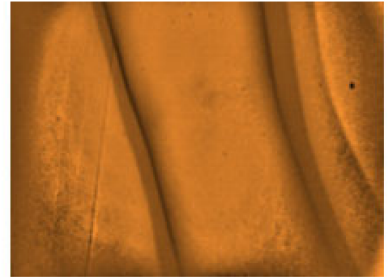

(b)

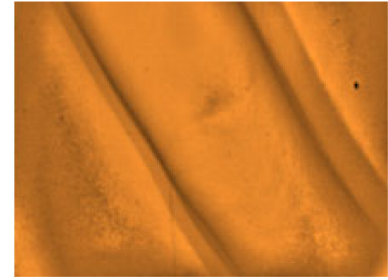

(c)

Figure 15. Arm images of three different subjects with $B M I=N$ with non-visible vein $(\mathbf{a}-\mathbf{c})$.

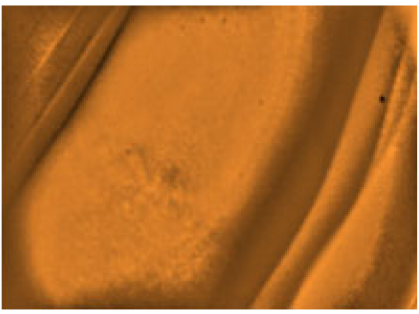

(a)

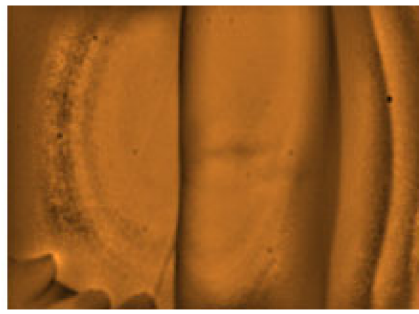

(b)

Figure 16. Arm images of two different child subjects with non-visible vein $(\mathbf{a}, \mathbf{b})$.

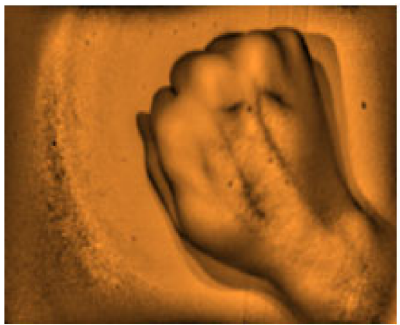

(a)

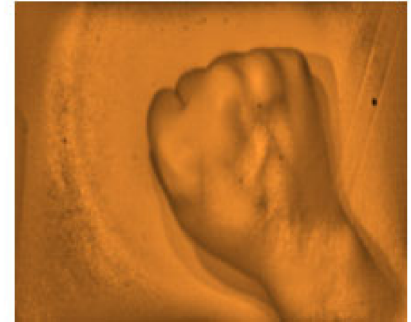

(b)

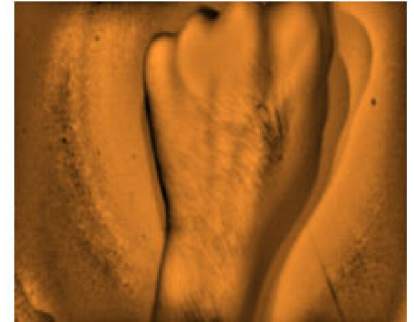

(c)

Figure 17. Dorsal hand images of three different subjects with hair structures with highly visible veins $(\mathbf{a}-\mathbf{c})$.

3.2.3. Dorsal Hand Site: Results for Highly Visible and Visible Subcutaneous Veins Were Presented Based on the Given Parameters

There were $57(61.29 \%)$ out of 93 male subjects and $64(42.95 \%)$ out of 149 female subjects with highly visible results, while $36(38.71 \%)$ male and 85 (57.05\%) female subjects in visible classification, as presented in Table 7. This shows that according to gender, males have vividly visible vein structures compared to females. Moreover, the markedly increased visible results in female subjects suggest that the vein finder is capable of making the dorsal hand veins image visible.

Table 7. Highly visible and visible according to gender.

\begin{tabular}{cccc}
\hline & No. of Subjects & Highly Visible & Visible \\
\hline Male & 93 & 57 & 36 \\
Female & 149 & 64 & 85 \\
TOTAL & 242 & 121 & 121 \\
\hline
\end{tabular}

Table 8 presents significantly increased visibility results of $10(83.33 \%)$ out of 12 child subjects, 21 (53.85\%) out of 39 middle aged adult, and six (60.00\%) out of 10 senior adult. This shows that, according to age, the device was able to improve visibility of veins in the dorsal hand among child, middle aged adult, and senior adult groups. While a higher result for highly visible was evident among young adult with 97 (53.59\%) out of 181 . 
Table 8. Highly visible and visible according to age.

\begin{tabular}{ccccc}
\hline & & No. of Subjects & Highly Visible & Visible \\
\hline Child & $0-15$ & 12 & 2 & 10 \\
Young adult & $16-30$ & 181 & 97 & 84 \\
Middle-aged adult & $31-50$ & 39 & 18 & 21 \\
Senior adult & $>50$ & 10 & 4 & 6 \\
TOTAL & & 242 & 121 & 121 \\
\hline
\end{tabular}

Table 9 presents significantly increased visibility results of 16 (66.67\%) out of 24 underweight subjects and $50(55.56 \%)$ out of 90 obese subjects. This indicates that, according to BMI, the vein finder was able to improve subcutaneous vein visibility in human subjects with below normal and even with increased BMI scores. While, higher results for highly visible were noted in normal and overweight BMI classifications, with $47(61.84 \%)$ out of 76 and $24(60.00 \%)$ out of 40 , respectively.

Table 9. Highly visible and visible according to BMI.

\begin{tabular}{ccccc}
\hline & & No. of Subjects & Highly Visible & Visible \\
\hline Underweight & $<18.5$ & 24 & 8 & 16 \\
Normal & $18.5-22.9$ & 76 & 47 & 29 \\
Overweight & $23-24.9$ & 40 & 24 & 16 \\
Obese & $\geq 25$ & 90 & 40 & 50 \\
& TOTAL & 230 & 119 & 111 \\
\hline
\end{tabular}

Table 10 presents significantly increased visibility results of $69(49.64 \%)$ out of 139 and $4(66.67 \%)$ out of 6 both in darker and dark complexion, respectively. This indicates that, according to skin color/tone classification, the vein finder was able to improve dorsal hand vein visibility, even in human subjects with increased skin pigmentation. Additionally, it is noted that the device was able to improve visibility in human subjects with light complexion, showing a result of four $(66.67 \%)$ visible out of six.

Table 10. Highly visible and visible according to skin color/tone.

\begin{tabular}{ccccc}
\hline & & No. of Subjects & Highly Visible & Visible \\
\hline Light complexion & II & 6 & 2 & 4 \\
Medium complexion & III & 91 & 47 & 44 \\
Darker complexion & IV & 139 & 70 & 69 \\
Dark complexion & V & 6 & 2 & 4 \\
TOTAL & & 242 & 121 & 121 \\
\hline
\end{tabular}

\section{Discussion}

In general, based on the performed clinical trials, the near infrared imaging system of the developed vein finder in this study has shown its capability as an efficient guiding device through real-time vein pattern recognition, for both dorsal hand and arm sites. The reliable NIR color spectrum and wavelength of $960 \mathrm{~nm}$ was used, and noted with increased optical absorption of hemoglobin, resulting in an image of a darker vein with lighter skin tissue background. Moreover, NIR was known to identify images of lesions with distinct appearances, like melanoma, basal cell and squamous cell carcinoma, microvascular and inflammatory lesions, dermatophytes, verrucae, etc. [32]. This augmented subcutaneous vein imaging study using the develop vein finder device was performed in a well lightened and ventilated room like a patient's room. Additionally, to maximize the assessment process, before the use of our vein finder, the researchers first investigated the veins on the target site, if it is visible or invisible with the naked eye. A total of 242 human subjects with variations as to gender, age, BMI, skin color/tone, and arm circumference were enrolled 
in the study. This is to validate the performance of the device by analyzing the captured vein images from the arm and dorsal hand sites. The intensity of the improved captured subcutaneous vein structures was compared through the use of the ImageJ software, as shown in Figure 10. The difference between the two (2) approaches, visual and digital imaging approach were quantitively compared, showing a remarkable improvement in the vein visibility, both in the arm and dorsal hand sites.

The vascular images that were captured by the vein finder prototype in the highly visible category showed a remarkable intensity ratio between the veins and the skin tissue background. While the $14(5.79 \%)$ non-visible results, which were considered as the limitation of this device in the arm site will be thoroughly explained in the latter part of the discussion. The researchers would like to emphasize that the visible results, as defined in this paper, to be the human subjects with veins' image only seen after using the vein finder, can be considered as the strength of this device, resulting in almost half of the subject population.

\subsection{Based on Parameters: Both Arm and Dorsal Hand Sites (for Highly Visible and Visible)}

Subcutaneous vein imaging can be challenged by different factors stated earlier. In consideration of those factors, the peripheral subcutaneous vein images were captured and analyzed while using the device. Having the results of increased highly visible among the males in both sites, these are associated with the observed physical visible vein structure which is larger compared to the veins of female subjects. The higher visible results in female subjects, also in both sites suggest that the device was able to capture vein images given the condition of having non-visible superficial veins observed with the naked eye. The device was able to improve the visibility of veins in child and middle-aged adult groups in both arm and dorsal hand sites. Although, subcutaneous fat and tiny veins of the young children are known factors that can affect vein visibility [22]. It makes venous access difficult to establish when compared to adults, particularly, among children younger than 3 years [13]. However, among senior adult group, vein visibility was also improved, as it was expected that vein size increases as we age, which is associated with the loss of elasticity in venous wall [45]. BMI as a parameter was considered in this study in accordance with previous studies relating to obesity as a factor, which may affect the visibility of the superficial veins $[5,11,21,31,38]$, even stating that difficulty in cannulation and venipuncture increases with the BMI of obese to morbidly obese range [46]. With regard to our results, the device was able to improve the vein visibility of more than half of the population under the obese range. The skin color is another consideration for the assessment. The studies show that skin pigments, primarily melanin, affect the vein's visibility $[5,21,22,31,38-41]$. It may cause challenges in locating the vein from individuals and races with darker skin tone. In this criterion, our device was able to improve the vein image of all the subjects with dark complexion in the arm site and more than fifty percent in the dorsal hand site.

The researchers included another parameter in order to maximize the assessment process. It is the measurement of the arm circumference in centimeter $(\mathrm{cm})$. This is to observe the relationship between the arm size and the vein visibility. The results showed that the arm circumference size is inversely proportional to the visibility of the peripheral arm veins. Additionally, the result revealed that the device was capable of improving the veins visibility even with subjects having 25 to $34 \mathrm{~cm}$ arm circumference.

\subsection{Results of Non-Visible in the Arm Site}

There are $14(5.79 \%)$ out of 242 subjects with non-visible peripheral subcutaneous veins, as shown in Table 9. Analysis of the results showed that as to gender, majority are female; as to age, many are in the young adult group, for BMI more than half of them are in obese category. With regard to skin tone, majority are in III and IV classification and one V. Finally, for the arm circumference, the majority is in the $25-29 \mathrm{~cm}$ group.

The result of the prototype testing on vein visibility of $94.21 \%$ (arm site) and $100 \%$ (dorsal hand site) as compared to the visibility of the vein without the device having $54.55 \%$ 
(arm site) and $50.00 \%$ (dorsal hand site), in consideration of all the parameters used and with the minimal component of the device, showed that the researchers were able to meet the aim in developing a low-cost real-time vein finder.

The capability of the developed NIR vein finder device was further shown through a comparative analysis between the gathered data from the experimentation that was performed with the 242 human subjects and the commercial vein finder devices, such as the AccuVein (AccuVein Inc.), VeinViewer Flex (Christie Medical Holdings Inc.), and VascuLuminator (De Koningh Medical Systems). The result of the analysis shows the advantages of the prototype based on the following: minimal used components, low-cost, reproducibility, and with its reliability rate in vein mapping/viewing as compared to commercial devices, see Table 11.

Table 11. Comparative analysis between the developed vein finder device and commercial vein finder devices with NIR technology.

1. Minimal used components (for the vein finder prototype) a. 3 NIR LED (Fongsam) $960 \mathrm{~nm}$

b. IR (IMX238 Sony) CMOS camera with IR filter

c. Free software and laptop as the image processing unit

d. Power consumption: $4.5 \mathrm{~V}$

e. Size: $7 \times 9 \times 10 \mathrm{~cm}$

f. Working distance: $15-20 \mathrm{~cm}$ g. Weight: $0.4 \mathrm{~kg}$
Commercial

Vein Finder Devices

1. AccuVein (AccuVein Inc.)

a. two safe barcode-scanner class lasers: an invisible

infrared and a visible red

b. Dual lens [47]

c. Projector system [48]

d. Power consumption: 3.6 V, 180 min lasting, $3100 \mathrm{mAh}$

e. Size: $5 \times 6 \times 20 \mathrm{~cm}$

f. Working distance: 10 to $45 \mathrm{~cm}$ g. Weight: $0.275 \mathrm{~kg}$ [47]

2. VeinViewer Flex (Christie Medical Holdings Inc.)

a. NIR light (Minimum of 5 lumens)

b. HD imaging and exclusive Df2

(digital full field) technology [49] c. Projector system [48]

d. Power consumption: Fast-swap lithium ion batteries or AC (outlet) Up to $2 \mathrm{~h}$ continuous run time per battery

e. Size: $29.464 \times 10.16 \times 4.318 \mathrm{~cm}$

f. Working distance: $30 \mathrm{~cm}$ g. Weight: $0.7 \mathrm{~kg}$ [49]

3. VascuLuminator (DKMP)

a. LED, SFH 4235, (Osram, Munich, Germany) $850 \mathrm{~nm}$ [22]

b. IR CCD camera with VGA resolution $(640 \times$ 480 ) and

adjustable focus lens with IR filter. [22]

c. Monitor LCD system [48]

d. Power consumption: DKMS bv charger type $330-00$ at least $8 \mathrm{~h}$

e. Size: $54 \times 48 \times 170 \mathrm{~cm}$ (when assembled) [50]

f. Working distance: $\sim 20 \mathrm{~cm}$ [22] g. Weight: $23 \mathrm{~kg}$ [50]

\begin{tabular}{ccc}
\hline $\begin{array}{c}\text { 2. Estimated cost in USD } \\
\text { (Highly reproducible based on its } \\
\text { production cost) }\end{array}$ & $80-100$ & 4000 to 7000 [36] \\
\hline $\begin{array}{c}\text { 3. Reliability Rate (\%) } \\
\text { a. Human in-vitro testing }\end{array}$ & $\begin{array}{c}\text { Arm site: } 94.21 \% \\
\text { Dorsal hand site: } 100.00 \% \\
\text { of the } 242 \text { human subjects }\end{array}$ & $93.00 \%$ [35] \\
\hline
\end{tabular}




\section{Conclusions}

In the study, it was presented that the developed simple vein finder device using NIR technology with low-energy consumption reflected light principle is highly efficient for real-time peripheral subcutaneous vein imaging. It is based on the analysis of the captured images real-time, using the naked eye as compared with the use of the device, on the arm and dorsal hand sites of 242 human subjects with varying gender, age, BMI, skin color/tone, and arm circumference. The results showed a remarkable increase in the vein visibility in general without the use of a tourniquet. The capability of the developed vein finder can be considered to be a useful guiding device in locating the vein for cannulation, providing venous access for blood sampling, therapy, and other medical purposes at a very low cost when compared to the commercially available vein finders. The developed vein finder can also be used by medical practitioners and students as an instructional tool for their training.

Author Contributions: Conceptualization, M.D.F.; and W.-F.C.; methodology, C.-T.P.; software, M.C.L.; validation, Z.-H.W., C.-F.L.; formal analysis, and investigation, Y.-L.S.; resources, M.D.F.; data curation, W.-F.C.; writing—original draft preparation, C.-T.P.; writing—review and editing, M.D.F.; visualization, M.-C.L.; supervision, Z.-H.W.; project administration, C.-T.P.; funding acquisition, C.-F.L. All authors have read and agreed to the published version of the manuscript.

Funding: This research was funded by Kaohsiung Armed Forces General Hospital, grant number 110-06.

Institutional Review Board Statement: The study was conducted according to the guidelines of the Declaration of Helsinki, and approved by the Institutional Review Board (or Ethics Committee) of TRINITY UNIVERSITY OF ASIA-Institutional Ethics Review Committee (TUA-IERC) (RP Code 2019-11-FRANCISCO-CMT-HEMOGLOBIN-V1, approved on March 2019).

Informed Consent Statement: Each participant of this study signed an informed consent prior to human testing. In addition, a parents' consent and assent forms were given and signed by participants with ages 17 and below.

Data Availability Statement: Data sharing is not applicable to this article.

Acknowledgments: This study was supported by grant 110-06 from Kaohsiung Armed Forces General Hospital.

Conflicts of Interest: The authors declare no conflict of interest.

Ethical Statement: The procedures performed in this study involving human participants were in accordance with the ethical standards of the Trinity University of Asia-Institutional Ethics Review Committee (TUA-IERC), approved on March 2019 with RP Code 2019-11-FRANCISCO-CMTHEMOGLOBIN-V1.

\section{References}

1. Fernández, R.; Armada, M. Multisensory System for the Detection and Localization of Peripheral Subcutaneous Veins. Sensors 2017, 17, 897. [CrossRef] [PubMed]

2. Lamperti, M.; Pittiruti, M., II. Difficult peripheral veins: Turn on the lights. Br. J. Anaesth. 2013, 110, 888-891. [CrossRef] [PubMed]

3. Scales, K. Intravenous therapy: A guide to good practice. Br. J. Nurs. 2008, 17, S4-S12. [CrossRef] [PubMed]

4. Lalongo, C.; Bernardini, S. Phlebotomy, a bridge between laboratory and patient. Biochemiamedica 2016, 26, 17-33.

5. Kimori, K.; Sugama, J.; Nakatani, T.; Tnakayama, K.; Miyati, T.; Sanada, H. An observational study comparing the pro-totype device with the existing device for the effective visualization of invisible veins in elderly patients in Japan. SAGE Open Med. 2015, 3, 2050312115615365. [CrossRef]

6. The Clinical \& Laboratory Standards Institute (CLSI). NEW CLSI Venipuncture Guidelines-CLSI, Collection of Diagnostic Venous Blood Specimens, Standard GP41, 7th ed; The Clinical \& Laboratory Standards Institute (CLSI): Annapolis Junction, MD, USA, 2017.

7. Buowari, O. Complications of venipuncture. Adv. Biosci. Biotechnol. 2013, 4, 126-128. [CrossRef]

8. Grable, H.; Gill, G. Phlebotomy Puncture Juncture Preventing Phlebotomy Errors-Potential For Harming Your Patients. Labmedicine 2005, 36, 430-433.

9. Pan, C.-T.; Francisco, M.D.; Yen, C.-K.; Wang, S.-Y.; Shiue, Y.-L. Vein Pattern Locating Technology for Cannulation: A Review of the Low-Cost Vein Finder Prototypes Utilizing near Infrared (NIR) Light to Improve Peripheral Subcutaneous Vein Selection for Phlebotomy. Sensors 2019, 19, 3573. [CrossRef] 
10. Parker, S.; Benzies, K.; Hayden, K.; Lang, E. Effectiveness of interventions for adult peripheral intravenous catherization: A systematic review and meta-analysis of randomized controlled trials. Int. Emerg. Nurs. 2017, 31, 15-21. [CrossRef]

11. Juric, S.; Flis, V.; Debevc, M.; Holzinger, A.; Zalik, B. Towards a Low-Cost Mobile Subcutaneous Vein Detection Solution Using Near-Infrared Spectroscopy. Sci. World J. 2014, 2014, 1-15. [CrossRef]

12. Goh, C.; Subaramaniam, R.; Saad, N.M.; Ali, S.A.; Meriaudeau, F. Subcutaneous veins depth measurement using diffuse re-flectance images. Opt. Express 2017, 25, 25741-25759. [CrossRef]

13. Rothbart, A.; Yu, P.; Müller-Lobeck, L.; Spies, C.; Wernecke, K.D.; Nachtigall, I. Peripheral intravenous cannulation with support of infrared laser vein viewing system in a pre-operation setting in pediatric patients. BMC Res. Notes 2015, 8, 463. [CrossRef]

14. West, J.; Atherton, J.; Costelloe, S.J.; Pourmahram, G.; Stretton, A.; Cornes, M. Preanalytical errors in medical laboratories: A review of the available methodologies of data collection and analysis. Ann. Clin. Biochem. Int. J. Lab. Med. 2017, 54, 14-19. [CrossRef]

15. Najat, D. Prevalence of Pre-Analytical Errors in Clinical Chemistry Diagnostic Labs in Sulaimani City of Iraqi Kurdistan. PLoS ONE 2017, 12, e0170211. [CrossRef]

16. Salinas, M.; López-Garrigós, M.; Flores, E.; Santo-Quiles, A.; Gutierrez, M.; Lugo, J.; Lillo, R.; Leiva-Salinas, C. Ten years of preanalytical monitoring and control: Synthetic Balanced Score Card Indicator. Biochem. Med. 2015, 25, 49-56. [CrossRef]

17. Patra, S.; Mukherjee, B.; Das, A. Pre-analytical errors in the clinical laboratory and how to minimize them. Int. J. Bioassays 2013. ISSN: 2278-778X.

18. Hammerling, J.A. A Review of Medical Errors in Laboratory Diagnostics and Where We Are Today: Table 1. Lab. Med. 2012, 43, 41-44. [CrossRef]

19. Lippi, G.; Chance, J.J.; Church, S.; Dazzi, P.; Fontana, R.; Giavarina, D.; Grankvist, K.; Huisman, W.; Kouri, T.; Palicka, V.; et al. Pre-analytical quality improvement: From dream to reality. Clin. Chem. Lab. Med. 2011, 49, 1113-1126. [CrossRef]

20. Goswami, B.; Singh, B.; Chawla, R.; Mallika, V. Evaluation of errors in a clinical laboratory: A one-year experience. Clin. Chem. Lab. Med. 2010, 48, 63-66. [CrossRef]

21. Chen, A.; Nikitczuk, K.; Nikitczuk, J.; Maguire, T.; Yarmush, M.L. Portable robot for autonomous venipuncture using 3D near infrared image guidance. Technology 2013, 1, 72-87. [CrossRef]

22. Cuper, N.; Verdaasdonk, R.; de Roode, R.; de Vooght, K.; Viergever, M.; Kalkman, C.; de Graaff, J. Visualizing Veins with NearInfrared Light to Facilitate Blood Withdrawal in Children. Clin. Pediatr. 2011, 50, 508-512. [CrossRef]

23. Liukui, C.; Zuojin, L.; Ying, W.; Yi, X. A design of infrared finger vein image acquisition terminal. Int. Conf. Bus. Manag. Electron. Inf. 2011, 4, 626-629. [CrossRef]

24. Marathe, M.; Bhatt, N.S.; Sundararajan, R. A Novel Wireless Vein Finder. In Proceedings of the International Conference on Circuits, Communication, Control and Computing, Bangalore, India, 21-22 November 2014; Institute of Electrical and Electronics Engineers: IEEE: Piscataway, NJ, USA; pp. 277-280.

25. Chakravorty, T.; Sonawane, D.N.; Sharma, S.D.; Patil, T. Low-cost subcutaneous vein detection system using ARM9 based single board computer. Int. Conf. Electron. Comput. Technol. 2011, 2, 339-343. [CrossRef]

26. Ayoub, Y.; Serhal, S.; Farhat, B.; Ali, A.; Amatoury, J.; Nasser, H.; Ali, M. Diagnostic Superficial Vein Scanner. In Proceedings of the 2018 International Conference on Computer and Applications (ICCA), Beirut, Lebanon, 25-26 August 2018; IEEE: Piscataway, New Jersey, USA, 2018. ISBN 978-1-5386-4371-6/18.

27. Kauba, C.; Uhl, A. Shedding Light on the Veins-Reflected Light or Transillumination in Hand-Vein Recognition. In Proceedings of the 2018 International Conference on Biometrics (ICB), Gold Coast, QLD, Australia, 20-23 February 2018; Institute of Electrical and Electronics Engineers (IEEE): Piscataway, NJ, USA; pp. 283-290.

28. Freeman, E.E.; Semeere, A.; Osman, H.; Peterson, G.; Rajadhyaksha, M.; González, S.; Martin, J.N.; Anderson, R.R.; Tearney, G.J.; Kang, D. Smartphone confocal microscopy for imaging cellular structures in human skin in vivo. Biomed. Opt. Express 2018, 9 , 1906-1915. [CrossRef]

29. Meng, G.C.; Shahzad, A.; Saad, N.M.; Malik, A.S.; Mériaudeau, F.; Chuan, M.G. Prototype design for wearable veins localization system using near infrared imaging technique. Colloq. Signal Process. Appl. CSPA 2015, 112-115. [CrossRef]

30. Ganesh, S. Depth and Size Limits for the Visibility of Veins Using the Vein Viewer Imaging System. Master's Thesis, The University of Tennessee, Memphis, TN, USA, 2007.

31. Chandra, F.; Wahyudianto, A.; Yasin, M. Design of vein finder with multi tuning wavelength using RGB LED. J. Phys. Conf. Ser. 2017, 853, 012019. [CrossRef]

32. Anderson, R.R. Lasers in dermatology—A critical update. J. Dermatol. 2000, 27, 700-705. [CrossRef]

33. Astner, S.; Anderson, R.R. Treating vascular lesions. Dermatol. Ther. 2005, 18, 267-281. [CrossRef] [PubMed]

34. Mela, C.A.; Lemmer, D.P.; Bao, F.S.; Papay, F.; Hicks, T.; Liu, Y. Real-time dual-modal vein imaging system. Int. J. Comput. Assist. Radiol. Surg. 2019, 14, 203-213. [CrossRef]

35. Peled, G.; Halak, M.; Blechman, Z. Peripheral vein locating techniques. Imaging Med. 2016, 8.

36. China Medical Solution (CMS) Limited. Dr. Waffle. Available online: https:/ / www.vein-finder.com (accessed on 20 September 2019).

37. Lima-Oliveira, G.; Volanski, W.; Lippi, G.; Picheth, G.; Guidi, G.C. Pre-analytical phase management: A review of the procedures from patient preparation to laboratory analysis. Scand. J. Clin. Lab. Investig. 2017, 77, 153-163. [CrossRef] 
38. Dhakshayani, M.; Yacin, S. Economically Affordable and Clinically Reliable Vein Finder. In Proceedings of the 30th Indian Engineering Congress, the 21st Century Engineering: The Make in India Pathway, Guwahati, India, 17-20 December 2015; pp. 63-69.

39. Shahzad, A.; Saad, M.N.; Walter, N.; Malik, A.S.; Mériaudeau, F. Hyperspectral venous image quality assessment for optimum illumination range selection based on skin tone characteristics. Biomed. Eng. Online 2014, 13, 109. [CrossRef] [PubMed]

40. Amipongongctrch, P.; Khaosomboon, K.; Keawgun, T. Design and Construction of Median Cubital Vein Transillumination Device by Using LED. In Proceedings of the 2015 8th Biomedical Engineering International Conference (BMEiCON), Pattaya, Thailand, 25-27 November 2015; Institute of Electrical and Electronics Engineers (IEEE): Piscataway, NJ, USA; pp. 1-4.

41. Wang, F.; Behrooz, A.; Morris, M.; Adibi, A. High-contrast subcutaneous vein detection and localization using multispectral imaging. J. Biomed. Opt. 2013, 18, 050504. [CrossRef] [PubMed]

42. Yarlagadda, A.; Murthy, J.; Prasad, M. A novel method for human age group classification based on correlation fractal di-mension of facial edges. J. King Saud Univ. Comput. Inf. Sci. 2015, 27, 468-476.

43. Lim, J.U.; Lee, J.; Kim, J.; Hwang, Y.; Kim, T.; Lim, S.; Yoo, K.; Jung, K.; Kim, Y.; Kook rhee, C. Comparison of World health Organization and Asia-Pacific body mass index classifications in COPD patients. Int. J. COPD 2017, 12, 2465-2475. [CrossRef]

44. Ash, C.; Town, G.; Bjerring, P.; Webster, S. Evaluation of a novel skin tone meter and the correlation between Fitzpatrick skin type and skin color. Photon Lasers Med. 2015, 4, 177-186. [CrossRef]

45. Krogera, K.; Oseb, C.; Rudofskya, G.; Roesenerb, J.; Weilandb., D.; Hircheb, H. Peripheral veins: Influence of gender, body mass index, age and varicose veins on cross-sectional area. Vasc. Med. 2003, 8, 249-255. [CrossRef]

46. Kam, J.; Taylor, D.M. Obesity significantly increases the difficulty of patient management in the emergency department. Emerg. Med. Australas. 2010, 22, 316-323. [CrossRef]

47. Accu Vein. Vein Visualization Technology. Available online: https://www.accuvein.com/why-accuvein/vein-visualizationtechnology/ (accessed on 15 June 2020).

48. Asrar, M.; Al-Habaibeh, A.; Houda, M. Innovative algorithm to evaluate the capabilities of visual, near infrared, and infrared technologies for the detection of veins for intravenous cannulation. Appl. Opt. 2016, 55, D67. [CrossRef]

49. Vein Viewer®Flex with HD Imaging and Df2 technology. Available online: https://christiemed.com/products/vienviewermodels/veinviewer-flex/ (accessed on 15 June 2020).

50. VascuLuminator Vein Imaging System Mk2 an Overview. Available online: https://www.do-pa.com/downloads/ Vasculuminator/VasculuminatorMk2.pdf (accessed on 15 June 2020). 